\title{
SALES AND VALUE CREATION: A SYNTHESIS AND DIRECTIONS FOR FUTURE RESEARCH
}

\author{
Alexander Haas, University of Giessen, Germany \\ Nina Stuebiger, University of Giessen, Germany
}

\begin{abstract}
How does the sales organization contribute to the creation of value to a firm and its customers? Understanding sales' pivotal role in the creation of value has been a long-standing goal of researchers and managers alike (Lindgreen and Wynstra 2005). Taking up the issue in their review of relevant literature, Haas, Snehota, and Corsaro (2011) convincingly argue that prior research has dealt with sales' value-creating role mostly per assumption and not systematically. Despite of scholars' extensive focus on sales' performance outcomes, the two most prominent salesperson behaviors under investigation in the sales literature (i.e., adaptive selling and customer-oriented selling) have been shown to account for only $9 \%$ or less of the variance in salesperson performance (Franke and Park 2006). And research that explicitly addresses the question of how the sales function adds value to the customer is still in its infancy. Accordingly, Singh and Koshy reflect (2010, p. 2): "we do not yet know if business-to-business salespersons actually create value in their relationship with customers".

The objective of this paper is to enhance the understanding of sales' role by examining the question of how value originates and is enhanced through sales in transactional and relational processes between business partners. Specifically, the paper investigates two main research questions: (1) What is the mechanism through which sales may contribute to the creation of value to the firm and its customers? (2) What are the organizational capabilities critical for sales to implement the valuecreating mechanism? To answer these questions, this paper synthesizes current empirical macro sales research and thus, (a) develops an interaction-based framework of sales' role in the creation of value; (b) suggests the concept of sales' valuecreating capabilities as a key mechanism for the creation of value; and, based on this framework, (c) identifies fruitful areas for future research which may guide systematic investigation of sales' value-creating role in business relationships.
\end{abstract}

The paper contributes to previous research by synthesizing current empirical macro sales research and providing an interaction-based framework of the value-creating role of sales. It integrates extant value and sales literature, proposes two perspectives of sales' role as value creator, and defines value creating capabilities as a set of organizational abilities related to a firm's sales function. This research is rooted in the concept of interaction and in line with current research on firms' capabilities (e.g., Morgan et al. 2009). To reflect the four intertwined characteristics of value-creating interactions (Haas, Snehota, and Corsaro 2011), sales functions' value-creating capabilities are conceptualized as consisting of four intertwined facets: mediating, initiating, realizing, and sense-making. These four dimensions of sales value creating capabilities serve as a key mechanism, which enhances our understanding of sales' role in the creation of value to the firm and its customers. As such, the present research provides a foundation for the systematic development of an interaction-based theory of value creation and sales' role in it.

In managerial terms, this paper highlights important areas sales managers should devote attention to (e.g., in terms of processes, sales training, etc.) in their efforts to create customer value and enhance sales performance. The proposed capabilities provide starting points for analyzing failures in the creation of customer value. Our results also inform firms about ways to design the sales function so that it will create customer value. Thus, our research supports firms and sales managers in their efforts to increase performance and customer value, and to strengthen the firms' competitive positions.

References available upon request.

Acknowledgement: We thank the Swiss National Science Foundation (SNSF) for a grant supporting this research. 